\title{
Pengembangan Indikator Waste (Sampah) pada Penerapan Konsep Green Campus di Itenas
}

\author{
SATRIO TRIADI AGUNG NUGROHO, EMMA AKMALAH, SITI AINUN
}

\author{
Jurusan Teknik Sipil, Institut Teknologi Nasional, Bandung \\ Email: satriotan@gmail.com
}

\begin{abstract}
ABSTRAK
Sampah merupakan salah satu faktor kerusakan lingkungan terutama di area kampus yang memiliki banyak timbulan sampah. Salah satu upaya untuk menyelamatkan lingkungan kampus adalah dengan menjalankan program green campus. Untuk menilai kegiatan green campus, Indonesia telah memiliki sistem penilaian yang dikeluarkan oleh Universitas Indonesia yaitu UI GreenMetric, dengan salah satu kategori yang dinilai adalah sampah. Penelitian ini bertujuan untuk mengembangkan indikator pada kategori sampah pada kampus Itenas, Bandung. Data yang diperlukan diperoleh melalui observasi dan studi literatur dan selanjutnya diolah dan dianalisis dengan metode pengembangan atau research and development. Hasil yang didapatkan adalah berupa perkembangan indikator dan sub-indikator yang dapat diterapkan di kampus Itenas yang juga dapat diterapkan di kampus lain.
\end{abstract}

Kata kunci: sampah, green campus, Itenas, pengembangan indikator

\begin{abstract}
Waste is one of the environmental damage factor, especially in campus areas that have a lot of waste generation. One of the efforts to save the campus environment is through the green campus program. To assess the green campus activities, Indonesia has a rating system issued by the University of Indonesia i.e UI GreenMetric, which has waste category. This study aims to develop indicators for waste category and applied at Itenas campus, Bandung. Data required for this research are obtained through observation and literature study and then processed and analyzed by research and development method. The results obtained are the development of indicators and sub-indicators that can be applied on the Itenas campus which can also be applied in other campuses.
\end{abstract}

Keywords: waste, green campus, Itenas, indicators development. 


\section{PENDAhUlUAN}

Kerusakan lingkungan dewasa ini adalah sebuah hal yang harus diperhatikan karena sangat mempengaruhi kehidupan di sekitarnya. Salah satu faktor perusak lingkungan adalah sampah. Timbulan sampah yang dihasilkan berbeda-beda jenisnya tergantung pada tempat dan aktivitasnya. Kampus adalah salah satu tempat yang menghasilkan berbagai jenis sampah, baik sampah rumah tangga maupun sampah lainnya.

Hingga saat ini telah banyak upaya-upaya yang dilakukan untuk memperbaiki kerusakan lingkungan salah satunya dengan penerapan konsep green campus. Green campus merupakan sebuah upaya yang dilakukan dalam upaya memperbaiki lingkungan terutama di area kampus. Mengingat kampus adalah tempat orang-orang berwawasan dan berpendidikan tinggi, maka pihak kampus harus peduli terhadap kehidupan di lingkungannya sendiri.

Perguruan tinggi yang memiliki visi untuk berperan aktif dalam pembangunan berkelanjutan di lingkup nasional dan global salah satunya adalah Institut Teknologi Nasional (Itenas) Bandung. Dengan visi yang sangat mendukung program pembangunan berkelanjutan ini, Itenas sudah mulai melakukan upaya untuk memperbaiki dan menjaga lingkungan.

Itenas akan menjadi lokasi penelitian dengan ruang lingkup program green campus pada kategori sampah yaitu (WS1) Policy to reduce the use of paper and plastic in campus, (WS2) Recycling program for university waste, (WS3) Toxic waste handled, (WS4) Organic waste treatment, (WS5) Inorganic waste treatment, dan (WS6) Sewerage disposal. Kategori ini terdapat pada standar penilaian green campus yang digunakan di seluruh dunia yaitu UI GreenMetric. Tujuan penelitian ini adalah untuk mengembangkan indikator sampah yang ada pada UI GreenMetric untuk diterapkan di Itenas dan di kampus lain di Indonesia.

\section{TINJAUAN PUSTAKA}

\subsection{Green Campus}

Green campus adalah program internasional mengenai pendidikan lingkungan, yang menawarkan kemantapan, cara untuk mengontrol pendidikan kampus agar berbasis lingkungan, serta inovasi dan penelitian dari departemen akademik dan menerapkannya pada manajemen sehari-hari di kampus (An Taisce, 2013). Green campus bertujuan untuk menumbuhkan kesadaran lingkungan di dalam wilayah kampus yang sekaligus dapat mengembangkan sikap dan komitmen yang bertanggung jawab terhadap lingkungan, baik di dalam kampus itu sendiri maupun di masyarakat luas.

\subsection{Badan Perancang Rating System untuk Green Campus}

Indonesia memiliki badan perancang rating system untuk green campus yaitu UI GreenMetric yang didirikan oleh Universitas Indonesia. Sebanyak 49 perguruan tinggi di Indonesia sudah mendaftarkan kampusnya dalam penilaian program green campus ini (GreenMetric UI World University Ranking, 2016). Perguruan tinggi di Indonesia yang menduduki peringkat 5 teratas dalam penilaian UI GreenMetric 2016 ini adalah Universitas Indonesia, Institut Teknologi Sepuluh November, Institut Pertanian Bogor, Universitas Diponegoro dan Universitas Sebelas Maret. Pada penilaian tahun 2016 tersebut Universitas Indonesia menduduki peringkat ke 31 dari 516 perguruan tinggi dari seluruh negara.

\subsection{Kategori Sampah UI GreenMetric}

UI GreenMetric memiliki 6 indikator terdiri atas beberapa sub-indikator seperti terlihat pada Tabel 1 (Greenmetric UI World University Ranking, 2016). 
Tabel 1. Indikator Sampah pada Greenmetric UI

\begin{tabular}{|c|c|c|}
\hline Indikator & Sub-indikator & Keterangan \\
\hline $\begin{array}{l}\text { (WS1) } \\
\text { Policy to reduce the use } \\
\text { of paper and plastic in } \\
\text { campus }\end{array}$ & $\begin{array}{l}\text { [1] None } \\
\text { [2] Double sided-printed policy program } \\
\text { [3] The use of tumbler } \\
\text { [4] The use of reusable bag } \\
\text { [5] Print when necessary }\end{array}$ & $\begin{array}{l}\text { Indikator ini membahas mengenai } \\
\text { kebijakan kampus dalam mengurangi } \\
\text { jumlah timbulan sampah kertas dan } \\
\text { plastik }\end{array}$ \\
\hline $\begin{array}{l}\text { (WS2) } \\
\text { Recycling program for } \\
\text { university waste }\end{array}$ & $\begin{array}{l}\text { [1] None } \\
\text { [2] Partial (less than } 25 \% \text { of waste) } \\
\text { [3] Partial (25\% - 50\% of waste) } \\
\text { [4] Extensive (more than } 50 \% \text { of waste) }\end{array}$ & $\begin{array}{l}\text { Indikator ini membahas mengenai } \\
\text { program daur ulang yang dilakukan } \\
\text { di dalam kampus }\end{array}$ \\
\hline $\begin{array}{l}\text { (WS3) } \\
\text { Toxic waste handled }\end{array}$ & $\begin{array}{l}\text { [1] Not managed } \\
\text { [2] Partly contained and inventoried } \\
\text { [3] Completely contained, inventoried and } \\
\text { handled }\end{array}$ & $\begin{array}{l}\text { Indikator ini membahas mengenai } \\
\text { cara kampus dalam mengelola limbah } \\
\text { beracun }\end{array}$ \\
\hline $\begin{array}{l}\text { (WS4) } \\
\text { Organic waste treatment }\end{array}$ & $\begin{array}{l}\text { [1] Open dumping } \\
\text { [2] Partly composted } \\
\text { [3] Partly composted and compost used } \\
\text { [4] Fully composted, compost used } \\
\text { [5] Fully composted, compost used } \\
\text { internally and externally }\end{array}$ & $\begin{array}{l}\text { Indikator ini membahas mengenai } \\
\text { pengelolaan sampah organik di } \\
\text { dalam kampus }\end{array}$ \\
\hline $\begin{array}{l}\text { (WS5) } \\
\text { Inorganic waste } \\
\text { treatment }\end{array}$ & $\begin{array}{l}\text { [1] Burned in open are } \\
\text { [2] Taken off campus to a dump site } \\
\text { [3] Partially recycled (less than 50\%) } \\
\text { [4] Fully recycled (more than 50\%) }\end{array}$ & $\begin{array}{l}\text { Indikator ini membahas } \\
\text { pengelolaan sampah anorganik } \\
\text { didalam kampus }\end{array}$ \\
\hline $\begin{array}{l}\text { (WS6) } \\
\text { Sewerage disposal }\end{array}$ & $\begin{array}{l}\text { [1] Disposed untreated to waterways } \\
\text { [2] Treated individually in septic tank } \\
\text { [3] Centralized treatment before disposal } \\
\text { [4] Treatment for recycling }\end{array}$ & $\begin{array}{l}\text { Indikator ini membahas mengenai } \\
\text { bagaimana kampus mengelola } \\
\text { saluran pembuangan air baik kotor } \\
\text { maupun bersih. }\end{array}$ \\
\hline
\end{tabular}

(Sumber: Greenmetric UI World University Ranking, 2016)

\section{METODOLOGI PENELITIAN}

Langkah pertama yang dilakukan dalam penelitian pengembangan indikator sampah UI GreenMetric adalah identifikasi masalah mengenai pengelolaan sampah di lingkungan kampus dan rumusan masalah untuk mengetahui kondisi eksisting pengelolaan sampah di Itenas. Metode pengembangan atau research and development yang digunakan membutuhkan data yang berupa data primer dan sekunder. Pengumpulan data primer berupa kegiatan yang didapat melalui observasi pada kegiatan kampus seperti perkuliahan, perkantoran, dan kegiatan umum, serta pengumpulan data sekunder mengenai infrastruktur Itenas dan studi literatur untuk mendukung data hasil observasi pada kegiatan serupa. Setelah melakukan pengumpulan data, selanjutnya dilakukan pengolahan data untuk mengetahui indikator dan sub-indikator yang akan dikembangkan serta analisis mengenai hasil pengembangan indikator yang dilakukan. Hasil penelitian yang didapatkan berupa indikator yang dikembangkan kemudian akan disimpulkan.

\section{PENGOLAHAN DAN ANALISIS DATA}

\subsection{Pengembangan Indikator}

Pada Sub-indikator UI GreenMetric akan dilakukan pengembangan berupa penambahan, pengurangan, dan modifikasi. Penambahan sub-indikator baru akan dilakukan apabila ada kegiatan yang berkaitan dengan sub-indikator awal namun tidak tercantum pada subindikator tersebut. Sub-indikator yang ditambahkan akan menjadi penilaian yang lebih detail dari penilaian indikator sebelumnya. 
Pengurangan sub-indikator akan dilakukan apabila kegiatan pada sub-indikator tersebut belum atau tidak dapat digunakan di dalam kampus. Pengurangan sub-indikator ini didasarkan pada peraturan yang berlaku dan perilaku kampus di Indonesia.

Modifikasi sub-indikator akan dilakukan apabila kegiatan pada sub-indikator awal dapat dijadikan item penilaian. Item penilaian ini digunakan untuk menilai penerapan sub-indikator dan setiap sub-indikator akan memiliki item penilaiannya sendiri. Pengembangan inilah yang dilakukan sehingga penilaian pada setiap indikator akan menjadi lebih detail. Pengembangan sub-indikator pada setiap indikator akan dijelaskan pada subbab selanjutnya.

\subsubsection{WS1 Policy to Reduce the Use of Paper and Plastic in Campus}

Indikator Policy to reduce the use of paper and plastic in campus menjelaskan mengenai kebijakan pengurangan kertas dan plastik di dalam kampus. Indikator Policy to reduce the use of paper and plastic in campus memiliki beberapa sub-indikator seperti yang sudah dijelaskan pada Tabel 1 sub-indikator pada WS1 Policy to reduce the use of paper and plastic in campus memiliki dua buah program untuk mereduksi kertas dan dua program untuk mereduksi plastik.

Melihat indikator ini hanya memiliki dua program untuk mengurangi timbulan sampah plastik dan dua program untuk mengurangi timbulan sampah kertas, maka pengembangan subindikator dapat dilakukan. Pengembangan ini dilakukan dengan cara menambahkan, modifikasi, atau menghilangkan sub indikator tersebut sesuai dengan kondisi yang dihadapi. Pengembangan indikator dilakukan berdasarkan observasi pada aktivitas di kampus seperti perkuliahan, himpunan mahasiswa, administrasi, dan kegiatan di area di luar ruangan kampus serta hasil studi literatur dengan program serupa. Pengembangan indikator ini dapat dilihat pada Tabel 2.

Tabel 2. Pengembangan Sub-indikator WS1 Policy to Reduce the Use of Paper and Plastic in Campus

\begin{tabular}{|c|c|c|c|c|c|}
\hline Sub-Indikator & \multicolumn{3}{|c|}{ Pengembangan } & \multirow[t]{2}{*}{ Observasi dan Studi Literatur } & Keterangan \\
\hline None & & & $*$ & & $\begin{array}{l}\text { Sub-indikator none ini dimodifikasi } \\
\text { dengan menjadikannya item penilaian } \\
\text { pada setiap indikator. }\end{array}$ \\
\hline $\begin{array}{l}\text { The use of } \\
\text { reusable bag }\end{array}$ & $*$ & & & $\begin{array}{l}\text { Observasi: } \\
\text { Penggunaan reusable bag ini belum digunakan } \\
\text { dalam aktivitas kampus dan mayoritas } \\
\text { masyarakat kampus menggunakan tas pribadi } \\
\text { berupa ransel dan tas sejenis. }\end{array}$ & $\begin{array}{l}\text { Sub-indikator ini dihilangkan karena } \\
\text { penggunaan reusable bag belum } \\
\text { digunakan dalam aktivitas kampus. } \\
\text { Penggunaan reusable bag pada di } \\
\text { Indonesia digunakan pada aktivitas } \\
\text { perbelanjaan, perpustakaan umum, } \\
\text { toko buku, dan tempat umum lainnya } \\
\text { yang membutuhkan tempat } \\
\text { penyimpanan barang bawaan } \\
\text { sementara. }\end{array}$ \\
\hline $\begin{array}{ll}\text { Double } & \text { sided- } \\
\text { printed } & \text { policy } \\
\text { program } & \end{array}$ & & * & & $\begin{array}{l}\text { Observasi: } \\
\text { Mahasiswa masih mencetak materi yang } \\
\text { diberikan oleh dosen pada kedua sisi kertas } \\
\text { untuk menghemat penggunaan kertas. }\end{array}$ & $\begin{array}{l}\text { Sub-indikator ini tetap digunakan } \\
\text { karena kegiatan ini masih umum } \\
\text { dilakukan di lingkungan kampus. } \\
\text { Pencetakan pada kedua sisi kertas } \\
\text { biasa digunakan dalam kegiatan non- } \\
\text { formal seperti mahasiswa mencetak } \\
\text { materi yang diberikan oleh dosen, } \\
\text { pengumuman, dan kegiatan non- } \\
\text { formal lainnya sehingga sub-indikator } \\
\text { ini tetap digunakan. }\end{array}$ \\
\hline
\end{tabular}


Tabel 2. Pengembangan Sub-indikator WS1 Policy to Reduce the Use of Paper and Plastic in Campus (Lanjutan)

\begin{tabular}{|c|c|c|c|c|}
\hline Sub-Indikator & Pengem & $\begin{array}{l}\text { bangan } \\
\text { B M }\end{array}$ & Observasi dan Studi Literatur & Keterangan \\
\hline The use of tumbler & $*$ & & $\begin{array}{l}\text { Observasi: } \\
\text { 1.Pengunaan plastik untuk makanan } \\
\text { lebih sedikit dibandingkan penggunaan } \\
\text { plastik untuk minuman. Plastik untuk } \\
\text { minuman lebih banyak digunakan } \\
\text { karena minuman dikemas dalam botol } \\
\text { plastik. } \\
\text { 2.Beberapa mahasiswa menggunakan } \\
\text { tempat minum sendiri. } \\
\text { Studi Literatur: } \\
\text { (UC Davis, 2017) } \\
\text { Kegiatan ini didukung oleh kampus } \\
\text { dalam bentuk kampus melakukan } \\
\text { penyediaan tempat isi ulang air minum } \\
\text { di beberapa titik di kampus. }\end{array}$ & $\begin{array}{l}\text { Sub-Indikator ini tetap ada karena } \\
\text { penggunaan tumbler sudah mulai } \\
\text { menjadi kebiasaan mahasiswa di } \\
\text { Indonesia. } \\
\end{array}$ \\
\hline Print when necessary & $*$ & & $\begin{array}{l}\text { Observasi: } \\
\text { Kegiatan ini masih sering dilakukan di } \\
\text { lingkungan kampus terutama pada } \\
\text { kegiatan perkuliahan. }\end{array}$ & $\begin{array}{l}\text { Sub-Indikator ini tetap ada karena } \\
\text { kegiatan sudah dilakukan hampir pada } \\
\text { seluruh kegiatan belajar dan perkantoran } \\
\text { di lingkungan kampus. }\end{array}$ \\
\hline $\begin{array}{l}\text { Penggunaan kertas } \\
\text { bekas (bagian } \\
\text { belakang kertas yang } \\
\text { masih kosong) untuk } \\
\text { keperluan lainya }\end{array}$ & & $*$ & $\begin{array}{l}\text { Observasi: } \\
\text { Beberapa mahasiswa menggunakan } \\
\text { kertas bekas sebagai media menulis } \\
\text { materi dan asistensi } \\
\text { Studi Literatur: (Okeniyi et al, 2012) } \\
\text { Penggunaan kertas lebih diutamakan } \\
\text { dengan menggunakan kertas bekas yang } \\
\text { selanjutnya akan didaur ulang sesuai } \\
\text { dengan banyaknya kertas yang } \\
\text { terbuang. }\end{array}$ & $\begin{array}{l}\text { Penggunaan kertas bekas untuk kegiatan } \\
\text { di dalam kampus digunakan lebih banyak } \\
\text { oleh mahasiswa. Penggunaan kertas } \\
\text { bekas ini digunakan dalam keperluan } \\
\text { mencatat materi ataupun mengerjakan } \\
\text { tugas yang bersifat asistensi. } \\
\text { a }\end{array}$ \\
\hline $\begin{array}{l}\text { Penggunaan media } \\
\text { online untuk } \\
\text { penyimpanan berkas } \\
\text { materi yang dapat } \\
\text { diakses dosen dan } \\
\text { mahasiswa }\end{array}$ & & $*$ & $\begin{array}{l}\text { Observasi: } \\
\text { Beberapa dosen sudah menggunakan } \\
\text { media online untuk memberikan materi } \\
\text { yang dapat diakses oleh mahasiswa } \\
\text { (Dilakukan di kampus dalam negeri yaitu } \\
\text { Telkom University, UNPAD, ITB) } \\
\text { Program ini dilakukan dalam bentuk } \\
\text { kebijakan penggunaan media online } \\
\text { sebagai tempat penyimpanan materi } \\
\text { untuk mahasiswa. }\end{array}$ & $\begin{array}{l}\text { Penambahan indikator ini karena } \\
\text { penggunaan media online bisa menjadi } \\
\text { salah satu cara untuk mengurangi } \\
\text { timbulan sampah kertas. Penggunaan } \\
\text { media online dalam perkuliahan sudah } \\
\text { mulai diterapkan di Indonesia. }\end{array}$ \\
\hline $\begin{array}{l}\text { Kegiatan lain untuk } \\
\text { mengurangi } \\
\text { penggunaan kertas dan } \\
\text { plastik }\end{array}$ & & $*$ & & $\begin{array}{l}\text { Penambahan Sub-Indikator ini dilakukan } \\
\text { karena adanya kemungkinan program } \\
\text { pengurangan kertas dan plastik lain yang } \\
\text { tidak disebutkan pada Sub-Indikator } \\
\text { sebelumnya. }\end{array}$ \\
\hline
\end{tabular}

\subsubsection{WS2 Recycling Program for University Waste}

Indikator Recycling program for university waste menjelaskan mengenai kegiatan daur ulang yang ada di dalam kampus yang memiliki beberapa sub-indikator seperti yang sudah dijelaskan pada Tabel $\mathbf{1}$. Sub-indikator yang ada pada indikator Recycling program for university waste memiliki sebuah program yang hanya menjelaskan berapa persen sampah yang didaur ulang tanpa mengetahui jenis sampahnya. Karena itu dilakukan pengembangan indikator untuk membuat penilaian yang lebih detail terhadap kegiatan daur ulang di dalam kampus.

Pengembangan indikator pada WS2 dilakukan dengan memodifikasi sub-indikator sebelumnya menjadi item penilaian pada sub-indikator yang baru. Sub-indikator none, partial (less than $25 \%$ of waste), partial (25\% - 50\% of waste), dan extensive (more than $50 \%$ of 
waste) akan dimodifikasi menjadi item penilaian pada sub-indikator yang baru. Modifikasi ini dilakukan untuk memberikan penilaian pada setiap sub-indikator menjadi lebih detail.

Pengembangan berupa penambahan sub-indikator juga dilakukan untuk mengetahui bagaimana pengelolaan pada kategori WS2. Pengembangan sub-indikator dilakukan dengan jenis sampah anorganik yang berbeda yaitu pada kertas, plastik, dan besi atau kaleng. Pengembangan indikator yang dilakukan dapat dilihat pada Tabel $\mathbf{3}$.

\section{Tabel 3. Pengembangan Indikator WS2 Recycling Program for University Waste}

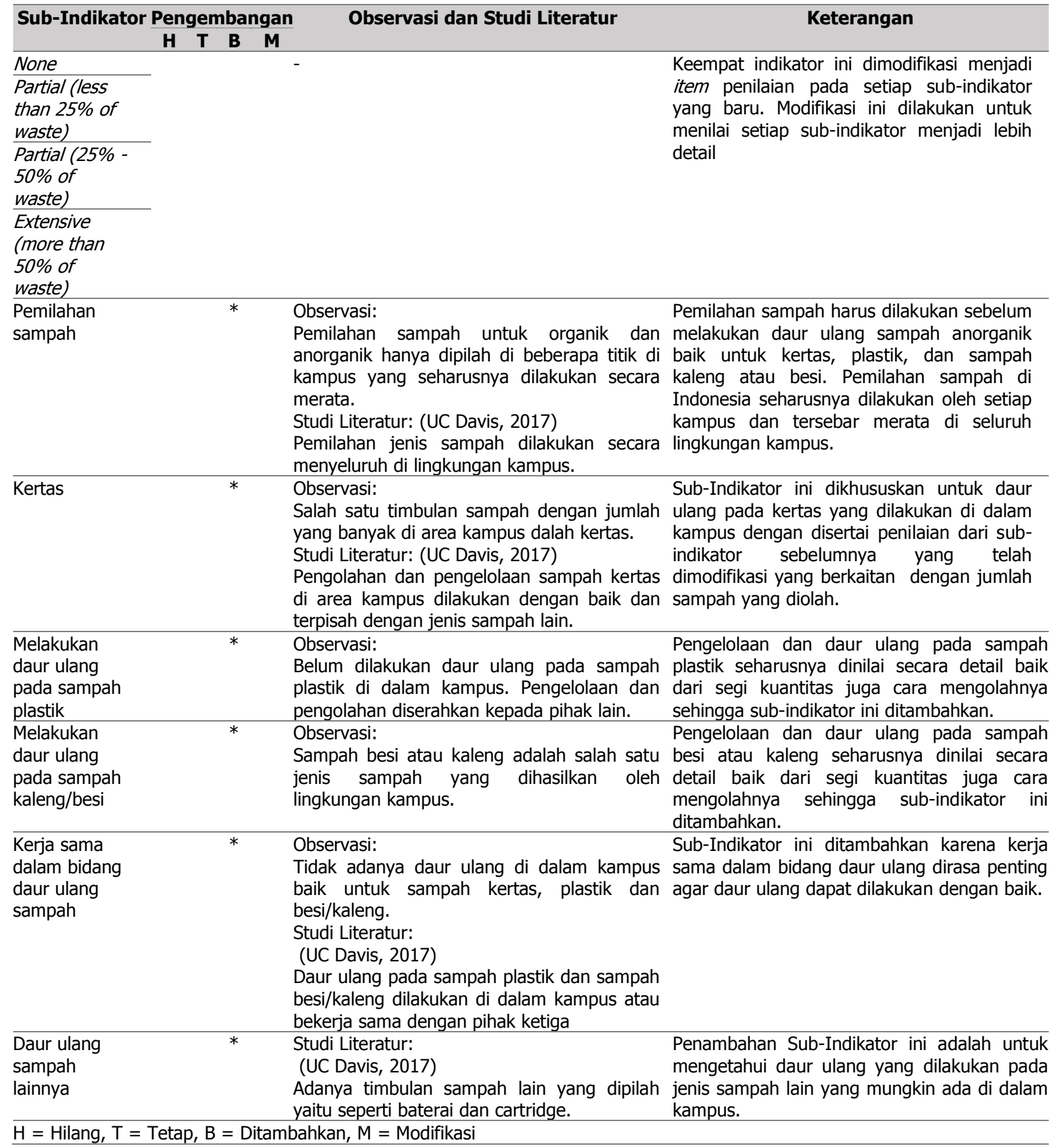

\subsubsection{WS3 Toxic Waste Handled}

Indikator Toxic waste handled menjelaskan bagaimana kampus mengelola limbah B3 (Bahan Berbahaya dan Beracun) yang dihasilkan. Mengingat kampus memiliki beberapa 
laboratorium yang menghasilkan limbah B3 baik limbah padat maupun cair, kampus seharusnya memiliki pengelolaan khusus terhadap limbah B3 ini. Dalam indikator ini terdapat beberapa sub-indikator yang dapat dilihat pada Tabel 1.

Sub-indikator pada WS3 ini yaitu none, partly contained and inventoried, dan completely contained, inventoried and handled tidak menjelaskan limbah B3 apa saja yang dibahas. Oleh karena itu sub-indikator ini dimodifikasi untuk dijadikan item pertanyaan yang lebih detail. Pada pengembangan ini, limbah B3 yang dilakukan pengelolaan dikhususkan pada limbah B3 padat yang dihasilkan melalui laboratorium. Penambahan sub-indikator dilakukan pada indikator WS3 ini. Tujuan penambahan ini adalah untuk memberikan penilaian yang lebih detail terhadap pengelolaan limbah B3 di kampus. Sub-indikator yang ditambahkan akan mengandung penilaian mengenai jenis pengelolaan dan jumlah yang dikelola. Subindikator mengenai kerja sama yang dilakukan oleh kampus pun akan ditambahkan untuk menilai pengelolaan yang lebih detail. Untuk lebih jelasnya penambahan yang dilakukan pada indikator ini dapat dilihat pada Tabel 4.

\section{Tabel 4. Pengembangan Indikator WS3 Toxic Waste Handled}

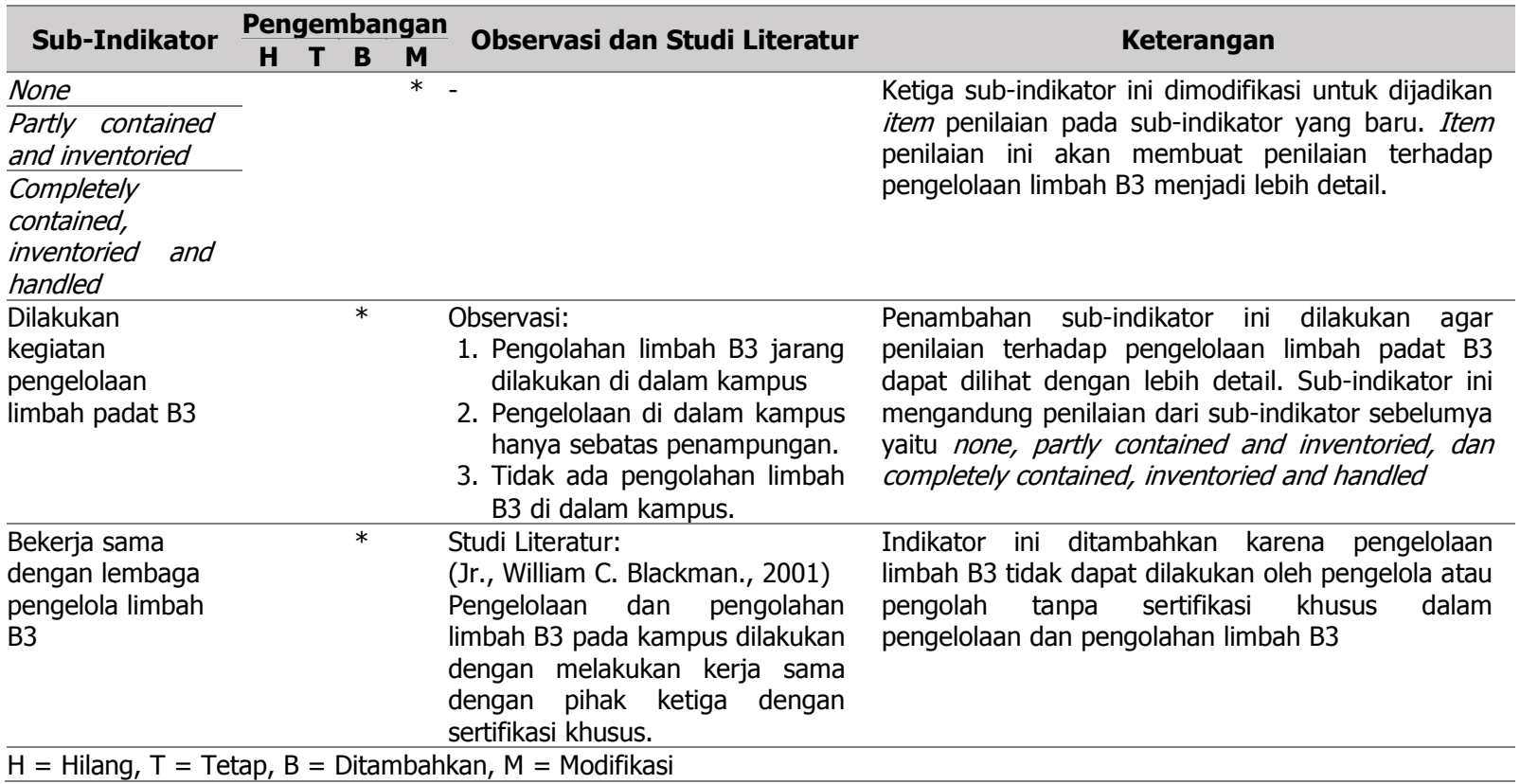

\subsubsection{WS4 Organic Waste Treatment}

Indikator Organic waste treatment menjelaskan bagaimana kampus mengelola sampah organik yang dihasilkan. Sub-indikator dalam indikator ini dapat dilihat pada Tabel 1. Indikator Organic waste treatment hanya membahas mengenai kompos, yang mana seharusnya pengolahan atau daur ulang pada sampah organik tidak hanya kompos, selain itu, terdapat pula sub-indikator open dumping yang dapat dimodifikasi menjadi item penilaian pada sub-indikator yang baru.

Pengembangan indikator dilakukan berdasarkan pada observasi pada kegiatan daur ulang sampah organik di kampus dan studi literatur dengan kegiatan serupa. Pengembangan ini dapat dilihat pada Tabel $\mathbf{5}$. 
Tabel 5. Pengembangan Indikator WS4 Organic Waste Treatment

\begin{tabular}{|c|c|c|c|c|}
\hline \multirow{2}{*}{ Sub-Indikator } & \multicolumn{2}{|c|}{ Pengembangan } & \multirow{2}{*}{$\begin{array}{c}\text { Observasi dan Studi } \\
\text { Literatur }\end{array}$} & \multirow{2}{*}{ Keterangan } \\
\hline & $\begin{array}{lll}\text { H } & \text { T } & \text { B }\end{array}$ & $\mathbf{M}$ & & \\
\hline $\begin{array}{l}\text { Open } \\
\text { (TPA) }\end{array}$ & & $*$ & $\begin{array}{l}\text { Observasi: } \\
\text { Kegiatan ini tidak dilakukan di } \\
\text { dalam kampus. }\end{array}$ & $\begin{array}{l}\text { Sub-indikator ini dapat dimodifikasi menjadi item } \\
\text { penilaian pada sub-kategori "Kerjasama dalam bidang } \\
\text { penanganan sampah organik" karena kegiatan ini } \\
\text { berkaitan dengan kerja sama antara kampus dengan } \\
\text { pihak lain pengelola sampah organik. }\end{array}$ \\
\hline Partly composted & & $*$ & $\begin{array}{l}\text { Observasi: } \\
\text { Pengolahan sampah organik } \\
\text { tidak hanya dalam bentuk } \\
\text { kompos, namun dapat berupa }\end{array}$ & $\begin{array}{l}\text { Sub-indikator ini dimodifikasi dengan menjadikannya } \\
\text { menjadi item penilaian pada sub-indikator baru yaitu } \\
\text { "Melakukan daur ulang pada sampah organik" }\end{array}$ \\
\hline
\end{tabular}
takakura, biodigester, dan biopori.

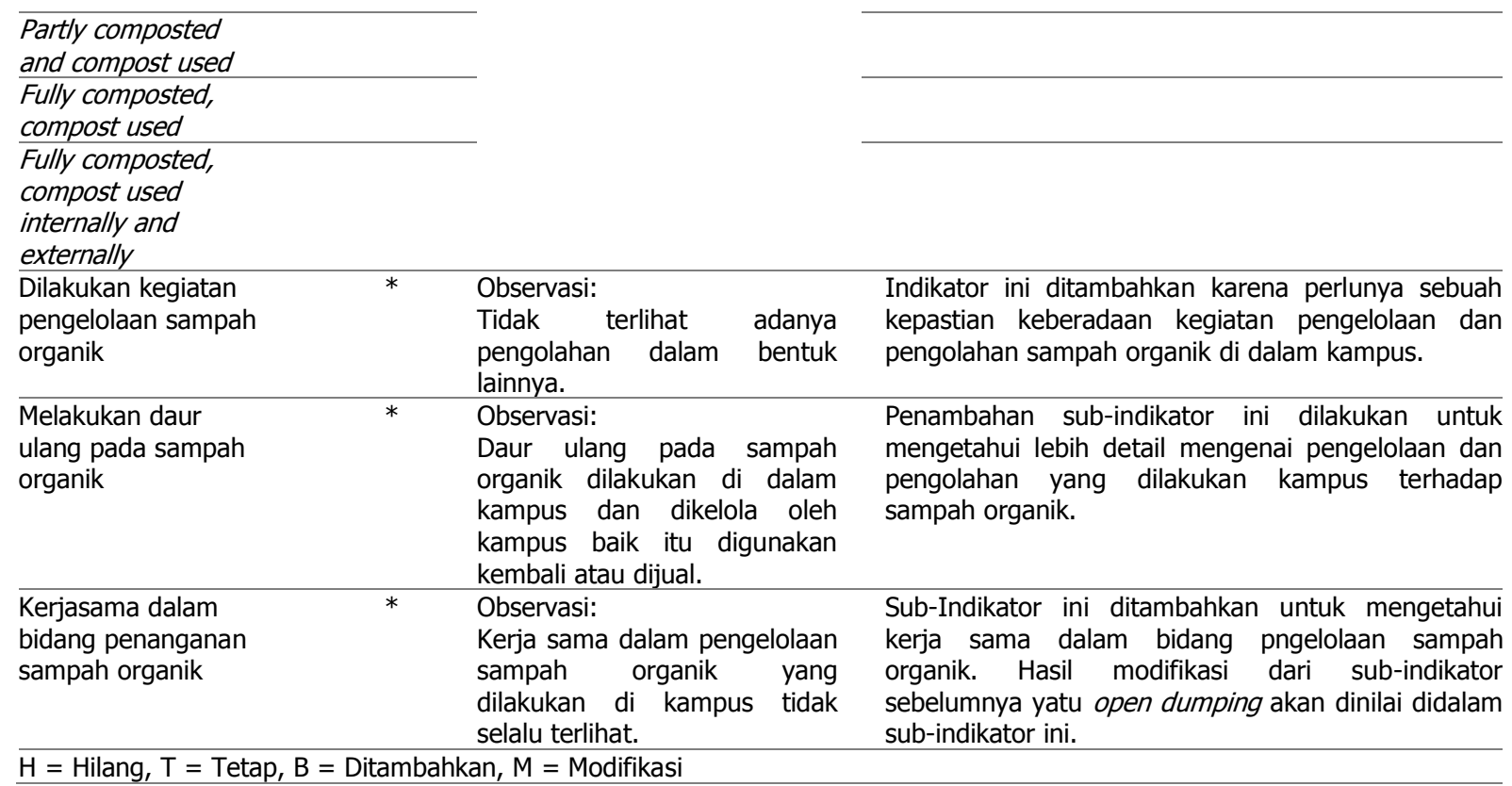

\subsubsection{WS5 Inorganic Waste Treatment}

Indikator Inorganic waste treatment menjelaskan mengenai pengolahan sampah anorganik di dalam kampus. Pengolahan sampah anorganik ini perlu dilakukan agar tidak mengakibatkan kerusakan lingkungan. Indikator ini memiliki sub-indikator yang dapat dilihat pada Tabel 1. Indikator Inorganic waste treatment memiliki beberapa kekurangan yaitu pada kegiatan burned in open area yang mana kegiatan ini sudah tidak boleh dilakukan di Indonesia sesuai dengan peraturan yang berlaku. Di samping itu, kegiatan taken off campus to a dump site yang sudah pasti dilakukan di kampus dan juga ada 2 kegiatan daur ulang yang sudah dibahas pada indikator WS2 Recycling program for university waste.

Dengan pertimbangan hal-hal yang telah disebutkan, maka dilakukan pengembangan untuk menyesuaikan indikator Inorganic waste treatment pada kondisi eksisting Itenas. Untuk pengembangan lebih detail dapat dilihat pada Tabel 6. 
Tabel 6. Pengembangan Indikator WS 5 Inorganic Waste Treatment

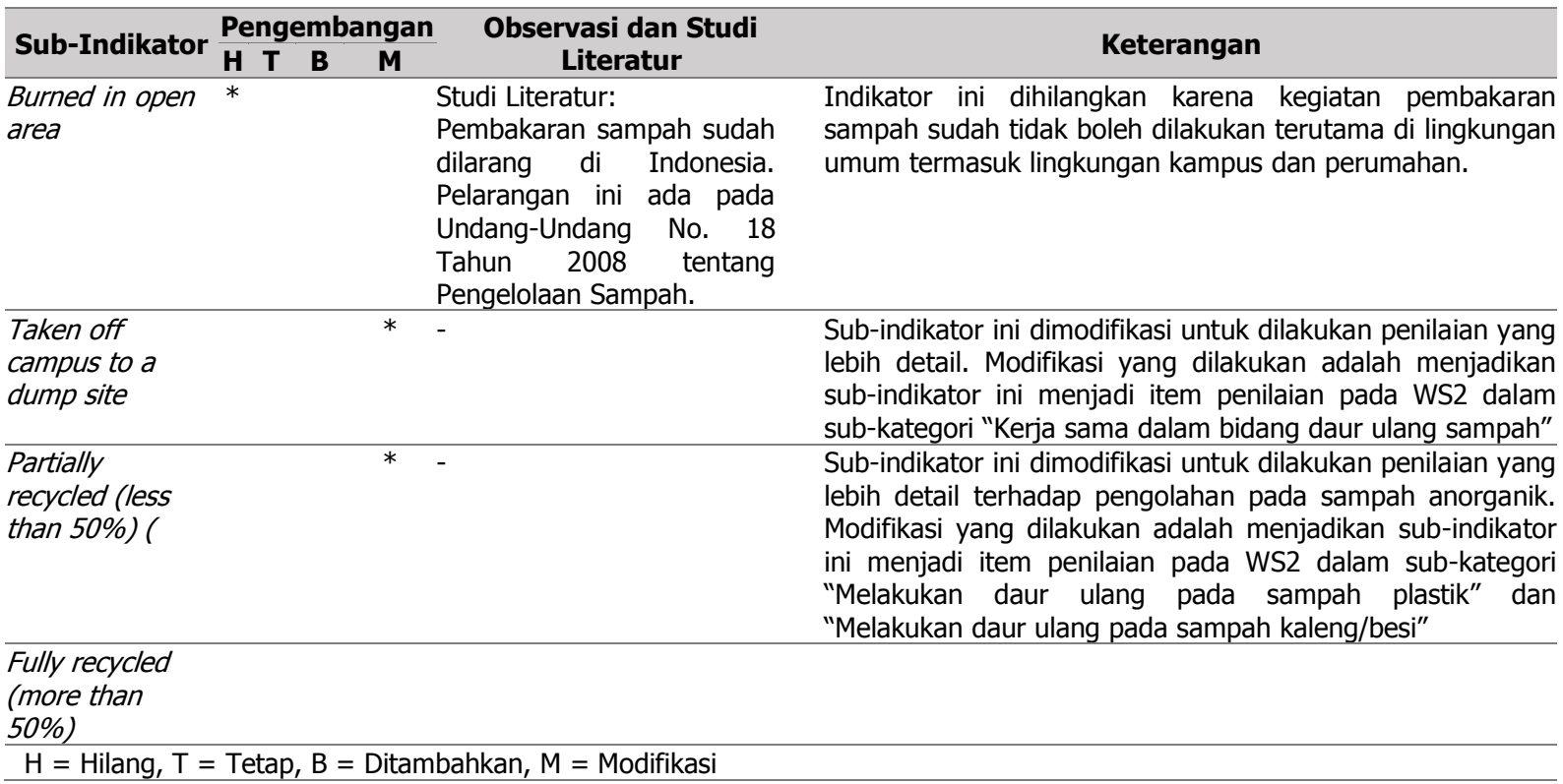

\subsubsection{WS6 Sewerage Disposal}

Indikator Sewerage disposa/ menjelaskan mengenai pengelolaan pembuangan limbah cair di dalam kampus. Pengelolaan pembuangan air kotor ini perlu diperhatikan karena kebutuhan air dan pembuangan limbah cair harus dikelola dengan baik sehingga tidak ada pencemaran terhadap lingkungan, terutama pada air bersih yang menjadi kebutuhan di dalam kampus. Sub-indikator ini dapat dilihat pada Tabel 1.

Indikator Sewerage disposa/ memiliki empat sub-indikator yang dilakukan dalam pengelolaan saluran pembuangan. Dalam penelitian ini pembuangan air limbah difokuskan kepada limbah cair domestik dan B3 yang dihasilkan kampus. Pengembangan indikator Sewerage disposal dilakukan berdasarkan hasil observasi pada kegiatan pengelolaan saluran dan studi literatur. Pengembangan indikator ini dapat dilihat pada Tabel 7.

Tabel 7. Pengembangan Indikator WS 6 Sewerage Disposal

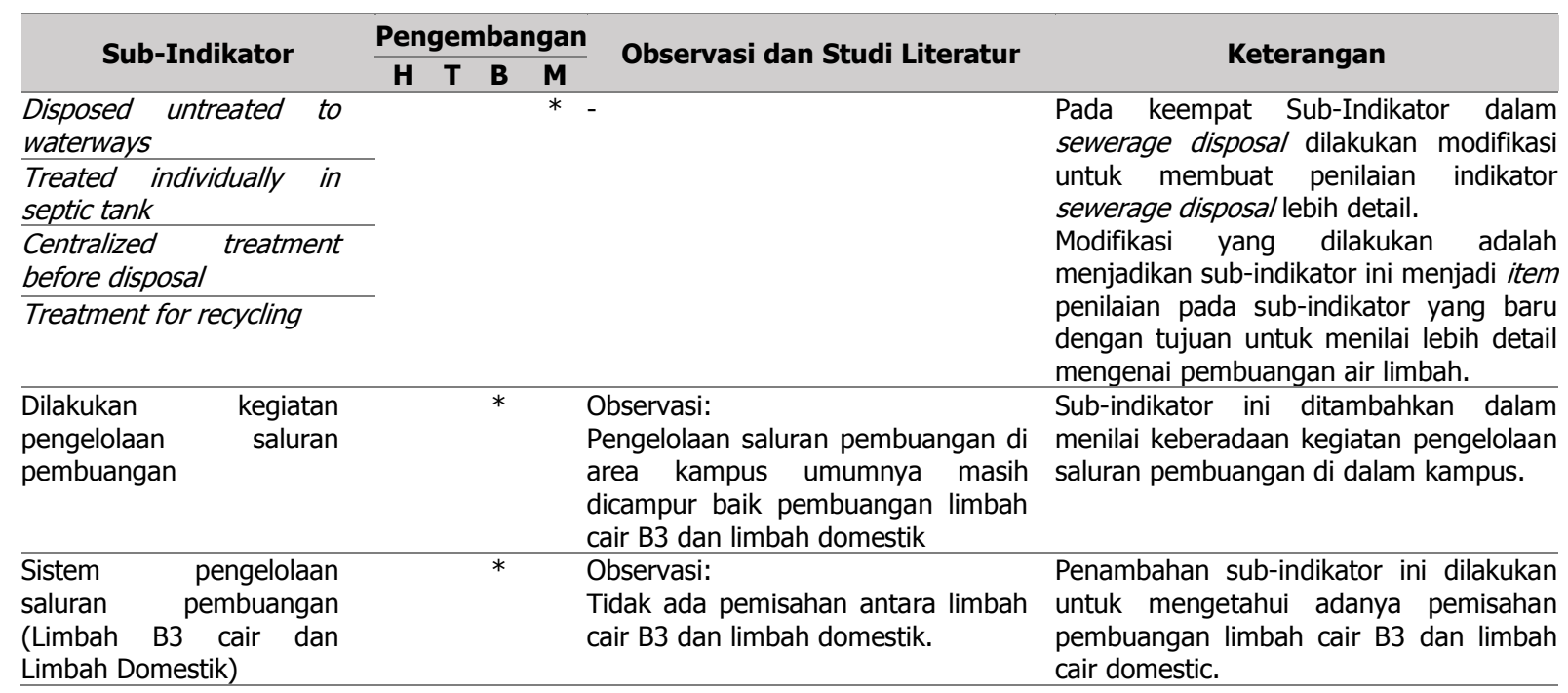


Tabel 7. Pengembangan Indikator WS 6 Sewerage Disposal

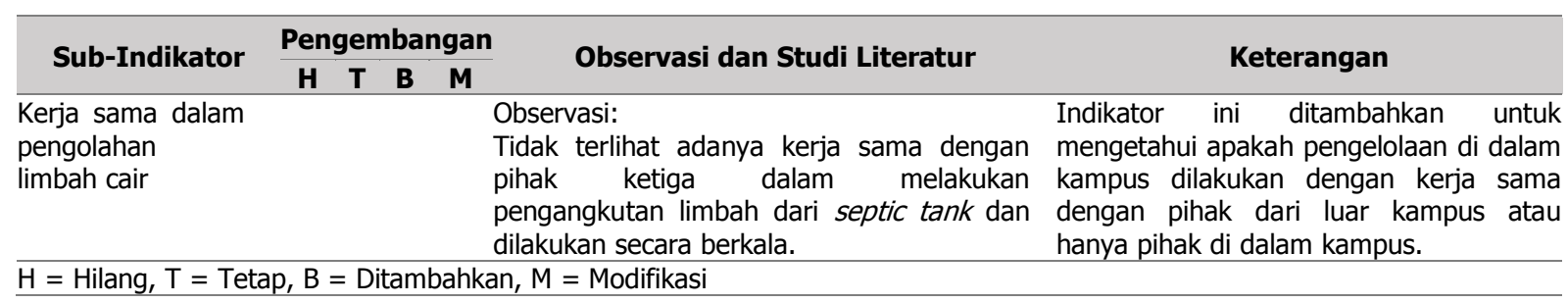

\subsection{Hasil Pengembangan Indikator}

Pengembangan indikator yang sudah dilakukan menghasilkan beberapa penambahan subindikator dan indikator yang dimodifikasi menjadi sebuah item penilaian.

Indikator WS1 Policy to Reduce the Use of Paper and Plastic in Campus dimodifikasi dengan pengurangan sub-indikator the use of recycle bag dan penambahan sub-indikator yaitu kegiatan penggunaan kertas bekas, penggunaan media online untuk penyimpanan berkas materi yang dapat diakses dosen dan mahasiswa, serta kegiatan lain untuk mengurangi penggunaan kertas dan plastik.

Indikator WS 2 Recycling Program for University Waste dimodifikasi dengan memodifikasi sub-indikator sebelumnya menjadi item penilaian. Kemudian adanya penambahan subindikator baru yaitu "Pemilahan Sampah", "Kertas", "Melakukan Daur Ulang Pada Sampah Plastik", "Melakukan Daur Ulang Pada Sampah Kaleng/Besi", "Kerja Sama dalam Bidang Daur Ulang Sampah", dan "Daur Ulang Sampah Lainnya".

Indikator WS 3 Toxic Waste Handled dimodifikasi dengan memodifikasi sub-indikator sebelumnya menjadi item penilaian. Kemudian dilakukan penambahan sub-indikator yang memiliki item penilaian dari sub-indikator sebelumnya yang dimodifikasi yaitu "Dilakukan Kegiatan Pengelolaan Limbah Padat B3" dan "Bekerja Sama dengan Lembaga Pengelola Limbah B3".

Indikator WS 4 Organic Waste Treatment dimodifikasi dengan memodifikasi sub-indikator sebelumnya yaitu pada penilaian kuantitas kompos menjadi item penilaian. Penambahan sub-indikator pun dilakukan pada indikator ini yaitu "Dilakukan Kegiatan Pengelolaan Sampah Organik", "Melakukan Daur Ulang Pada Sampah Organik", dan "Kerja Sama dalam Bidang Penanganan Sampah Organik".

Indikator WS 5 Inorganic Waste Treatment tidak digunakan karena indikator ini telah dinilai lebih detail pada indikator WS 2 recycling program for university waste.

Indikator WS 6 berubah nama menjadi WS 5 Sewerage Disposal dimodifikasi dengan memodifikasi pada sub-indikator sebelumnya yang hanya membahas mengenai pengelolaan pembuangan limbah cair menjadi beberapa sub-indikator yang lebih detail yaitu penambahan indikator "Dilakukan kegiatan pengelolaan saluran pembuangan", "Sistem pengelolaan saluran pembuangan (Limbah B3 cair dan Limbah Domestik) ", dan "Kerja sama dalam pengelolaan limbah cair".

\section{KESIMPULAN}

Indikator pada UI GreenMetric sudah memiliki kegiatan yang baik untuk memperbaiki kondisi lingkungan di kampus. Akan tetapi masih harus dilakukan pengembangan pada subindikatornya. Pengembangan ini disesuaikan dengan keadaan eksisting persampahan dan aktivitas masyarakat kampus di Indonesia. Pemembangan yang dilakukan akan membuat penilaian terhadap setiap indikator menjadi lebih detail dan mendalam dengan melakukan penambahan kegiatan yang dapat dilakukan, modifikasi kegiatan yang sudah ada, dan menghilangkan kegiatan yang tidak bisa dilakukan dalam kampus sehingga didapatkan indikator dengan sub-indikator yang lebih detail yang dapat diterapkan di lingkungan kampus Itenas dan kampus lain dengan jenis kegiatan serupa. 
Pengembangan Indikator Waste (Sampah) pada Penerapan Konsep Green Campus di Itenas

\section{DATAR RUJUKAN}

An Taisce, Enviromental Education Unit. (2013). The Green-Campus Programme. Dipetik Juli 25, 2017, dari Trinity Collage Dublin: https://www.tcd.ie/GreenPages/documents/Green-Campus\%20Guidebook\%2020132014.pdf

Dewan Perwakilan Rakyat. (2008). Undang-Undang Republik Indonesia Nomor 18 Tahun 2008 Tentang Pengelolaan Sampah. Jakarta, Indonesia: Dewan Perwakilan Rakyat.

Blackman, Jr. W. C. (2001). Permits to Treat, Store, or Dispose of Hazardous Waste. In W. C. Jr., Basic Hazardous Waste Management Third Edition. Washington, D.C.: CRC Press LLC.

Okeniyi, Olusegun,J., Anwan, Udonwan,E. (2012). Caracterisation and Implication for Sustainable Waste Management. Solid Wastes Generation in Covenant Uiversity, Ota, Nigeria. 3(2), 419-424

UC Davis. (2017, 7 28). Sustainable 2nd Centuries UC Davis Take Action: Recycle. Dipetik dari Sustainable 2nd Centuries University of California Davis: http://sustainability.ucdavis.edu/action/zero_waste/recycle.html

Universitas Indonesia. (2016, 2 10). UI Greenmetric World University Ranking. UI Greenmetric World University Ranking Guideline, P. 1. Jakarta: Universitas Indonesia. 